\title{
PRO-ATHEROGENIC LIPID PROFILE IN PULMONARY TUBERCULOSIS PATIENTS WITH CONCURRENT INSULIN RESISTANCE
}

\author{
Shvets Olga ${ }^{1}$, Shevchenko Olga ${ }^{1}$, Piskur Zoriana ${ }^{2}$, \\ Stepanenko Hanna ${ }^{1}$, Pohorielova Olha ${ }^{1}$ \\ ${ }^{1}$ Kharkiv National Medical University, Kharkiv, Ukraine \\ ${ }^{2}$ Danylo Halytsky Lviv National Medical University, Lviv, Ukraine
}

https://doi.org/10.35339/ic.8.2.111-114

\begin{abstract}
Background. The problem of studying lipid metabolism in patients with tuberculosis is of interest to scientists around the world. The purpose of the study was to investigate lipid profile in pulmonary tuberculosis patients with concurrent insulin resistance. Materials and methods. Forty-one patients with pulmonary tuberculosis were examined. Insulin resistance index (HOMA-IR), total cholesterol level (TC), triglycerides (TG) level, high density lipoprotein (HDL) cholesterol, low density lipoprotein (LDL) cholesterol, very-low-density lipoprotein (VLDL) cholesterol and atherogenic index (AI) were measured. The patients were divided into two groups: group $1-26$ patients with tuberculosis and insulin resistance (HOMA-IR > 2.7); group $2-15$ patients with tuberculosis without insulin resistance (HOMAIR <2.7). Results. Group 1 patients had severe course of TB with fever, severe fatigue and weakness, profuse sweating, weight loss, cough and shortness of breath. Median TC indices differed at significant level $(\mathrm{p}=0.012)$ : group $1-4.82 \mathrm{mmol} / \mathrm{L}$, group $2-4.25 \mathrm{mmol} / \mathrm{L}$. TG level was higher in group 1 patients $-1.32 \mathrm{mmol} / \mathrm{L}$ than in group 2 patients $-1.28 \mathrm{mmol} / \mathrm{L}$. LDL cholesterol values were higher in group 1 patients $-3.2 \mathrm{mmol} / \mathrm{L}$, vs. group 2: $2.5 \mathrm{mmol} / \mathrm{L}$. The AI was higher in group1 $(\mathrm{p}=0.005)$ : 3.9 units against 2.8 units in group 2 patients. Conclusions. Insulin resistance in pulmonary tuberculosis patients was associated with severe course of the disease, severe clinical manifestations and impaired external respiration. Pro-atherogenic disorders of lipid metabolism in pulmonary tuberculosis patients with concurrent insulin resistance can be considered as the degree of endogenous intoxication. Keywords: pulmonary tuberculosis, insulin resistance, lipid disorders.
\end{abstract}

\section{Introduction}

Lipids play an essential role in life processes. As one of the main components of biological membranes, lipids affect their permeability, participate in the transmission of nerve impulses, and the creation of intercellular contacts. Fat serves as a very efficient source of energy in the body, either directly or potentially in the form of stored adipose tissue $[1,2]$.

The scientific data on the effect of lipid metabolism on the immune reactivity of the body are extremely contradictory and contain information about both the development of metabolic immunosuppression and the activation of the immune system function $[3,4]$.

\footnotetext{
Corresponding Author:

Olga Shvets, MD, PhD, Department

of Phthisiology and Pulmonology, Kharkiv National

Medical University, Kharkiv, Ukraine.

E-mail: olga.shvets@ukr.net
}

The state of lipid metabolism in tuberculosis patients has long been considered an important component of the immunobiological state of the organism, although the assessment of the nature of these connections has undergone dramatic changes over time. Today the overwhelming majority of researchers consider total cholesterol in the biological environment of the host organism as a contributing factor to persistence and replication of $\mathrm{M}$. tuberculosis. The problem of studying the indices of lipid metabolism in patients with tuberculosis (TB) for many years is of interest to scientists around the world $[5,6]$. It is known that TB is accompanied by severe disorders of lipid metabolism of the macroorganism, which subsequently acquire the quality of independent factors, and can independently affect the further course of the disease and the outcome of treatment. Even more severe manifestations of dyslipidemia are observed in patients with 
combined pathology of tuberculosis / diabetes mellitus [7]. Elevated insulin levels stimulate lipogenesis de novo in hepatocytes, but are unable to inhibit lipolysis in insulin-resistant adipose tissue cells - adipocytes, which leads to increased free fatty acids in the liver and the formation of excessive amounts of low and very low density lipoproteins. The state of lipid metabolism in patients with TB against a background of concomitant insulin resistance (IR) is not well understood. Therefore, this issue has attracted our attention.

\section{Purpose, subjects and methods}

1.1. The purpose of the study was to investigate lipid profile in pulmonary tuberculosis patients with concurrent insulin resistance.

\subsection{Subjects and methods}

Forty-one patients with firstly-diagnosed pulmonary tuberculosis were included in the study. The patients with co-morbid pathology (diabetes mellitus, chronic nonspecific lung disease, chronic hepatitis, HIV / AIDS) were excluded from the study. Data from patients who were overweight $($ BMI $>25)$ were not taken into account when calculating the body mass index. The study did not include children and adolescents, the elderly, pregnant women, people from vulnerable groups, and patients who did not consent to the processing of personal information. The study was approved by the ethics commission of the Kharkiv National Medical University. Examination and diagnosis were made according to the current order of the Ministry of Health of Ukraine. All participants of the study underwent an oral glucose tolerance test, determined fasting insulin levels, and insulin resistance index (HOMA-IR) and body mass index (BMI) were calculated. Total cholesterol level (TC), triglycerides (TG) level, high density lipoprotein (HDL) cholesterol, low density lipoprotein (LDL) cholesterol, very-low-density lipoprotein (VLDL) cholesterol and atherogenic index (AI) were also measured.

For statistical data processing, a package of general-purpose data processing programs Statistica for Windows version 13.2 was used. At the first stage of calculation, descriptive statistics were obtained for indicators measured on a quantitative scale. Such characteristics included median and mean as a measure of position; standard deviation and quartiles as measures of scattering; minimum and maximum value as indicators of sample size. Kolmogorov-Smirnov criterion was used to verify the coincidence of the distribution of quantitative indicators with the normal one in the groups. Because the law of distribution of the studied numerical indicators differed from the normal one, the statistical significance was checked using the MannWhitney U-test. Qualitative traits were compared using the Pearson test $\chi^{2}$. The differences were considered statistically significant at $\mathrm{p}<0.05$.

\section{Results \& Discussion}

According to the calculation of the HOMA-IR, patients were divided into two groups. Group 1 consisted of 26 patients with pulmonary tuberculosis and insulin resistance (TB/IR) (HOMAIR > 2.7); Group 2 - consisted of 15 patients with pulmonary tuberculosis without insulin resistance (TB) (HOMA-IR $<2.7$ ). The age of patients ranged from 20 to 55 years. The age groups were identical. By sex, patients in Group 1 (TB / IR) were almost halved: $58.85 \%$ of the group were men (14 people) and $46.15 \%$ (12 patients) were women. Among the surveyed Group 2 (TB), the vast majority (93.33 \%, 14 patients) were men. This distribution was statistically significant, $\mathrm{p}<0.01$.

The vast majority of patients in Group 1 (TB / IR) (17 patients $(65.4 \%)$ ) were identified at the time of treatment and indicated the presence of intoxication and "chest" complaints, which bothered them from 2 weeks to 2 months, while patients of Group 2 (TB) were detected mostly actively, during a screening chest $\mathrm{x}$-ray examination (8 patients $(53.3 \%)$ ) and did not notice any deviations in general well-being and health status (Table 1).

Radiologically, patients of both groups were characterized by bilateral lung lesions: group 1 (TB / IR) - 15 patients $(57.7 \%)$, group 2 (TB) 12 patients $(80 \%)$. The predominant clinical form was infiltrative TB (group 1 (TB / IR) - $88 \%$, group 2 (TB) $-100 \%$ ), although among the patients of group 1 there were other, more severe forms of the disease: fibro-cavernous $-8 \%$ and disseminated $-4 \%$. Almost the same proportion of patients in both groups had destructive changes in the lungs: 16 patients $(61.5 \%)$ of group 1 (TB / IR) and 9 patients $(60 \%)$ of group 2 (TB). However, when determining the function of external respiration, half of patients with insulin resistance (13 people - $50 \%$ ) were found to have respiratory disorders of a mixed type of extremely severe severity, while patients without insulin resistance only 6 patients had such changes $(15.38 \%))(p=0.005)$.

As a result of the comparison of lipid metabolism indices between examined groups, we found significant difference in the levels of total cholesterol, low-density lipoprotein cholesterol and the atherogenic index $(\mathrm{p}<0.05)($ Table. 2$)$. 
Table 1

Patient's complaints

\begin{tabular}{|l|c|c|}
\hline \multicolumn{1}{|c|}{ Complaints } & Group 1 (TB/IR) & Group 2 (TB) \\
\hline Weakness & $18(69.2 \%)$ & $7(46.6 \%)$ \\
\hline Fatigue & $15(57.7 \%)$ & $4(33.3 \%)$ \\
\hline Loss of appetite & $8(30.8 \%)$ & $7(46.7 \%)$ \\
\hline Low grade fever & $16(61.5 \%)$ & $2(13.3 \%)$ \\
\hline Fever & $8(30.8 \%)$ & $6(40 \%)$ \\
\hline Increased sweating & $17(65.4 \%)$ & $6(40 \%)$ \\
\hline Wet cough & $18(69.2 \%)$ & $1(6.7 \%)$ \\
\hline Dry cough & $6(23.1 \%)$ & $1(6.7 \%)$ \\
\hline Pain in the chest & $4(15.4 \%)$ & $4(26.7 \%)$ \\
\hline Weight loss & $13(50 \%)$ & 0 \\
\hline Dyspnea & $8(30.8 \%)$ & \\
\hline
\end{tabular}

Lipid metabolism indices of examined patients

\begin{tabular}{|l|c|c|c|c|c|}
\hline \multicolumn{1}{|c|}{ Indices } & Mean & Median & Min & Max & Std.Dev. \\
\hline \multicolumn{7}{|c|}{ Group 1 } \\
\hline Total cholesterol, mmol/L & 4.53 & $4.82^{*}$ & 3.33 & 7.95 & 0.43 \\
\hline Triglycerides, mmol/L & 1.28 & 1.32 & 1.17 & 1.48 & 0.09 \\
\hline HDL cholesterol, mmol/L & 1.16 & 1.13 & 0.98 & 1.45 & 0.17 \\
\hline LDL cholesterol, mmol/L & 3.14 & $3.2^{* *}$ & 1.6 & 6.5 & 0.44 \\
\hline VLDL cholesterol, mmol/L & 0.59 & 0.56 & 0.51 & 0.66 & 0.04 \\
\hline Atherogenic index, units & 2.78 & $3.9^{* * *}$ & 1.89 & 3.52 & 0.54 \\
\hline \multicolumn{7}{|l|}{ Group 2 } \\
\hline Total cholesterol, mmol/L & 4.30 & $4.25^{*}$ & 2.94 & 6.08 & 0.66 \\
\hline Triglycerides, mmol/L & 1.24 & 1.28 & 1.12 & 1.36 & 0.09 \\
\hline HDL cholesterol, mmol/L & 1.14 & 1.17 & 0.97 & 1.26 & 0.11 \\
\hline LDL cholesterol, mmol/L & 2.63 & $2.5^{* *}$ & 1.0 & 4.3 & 0.62 \\
\hline VLDL cholesterol, mmol/L & 0.56 & 0.58 & 0.51 & 0.62 & 0.04 \\
\hline Atherogenic index, units & 2.31 & $2.8^{* * *}$ & 2.10 & 3.15 & 0.45 \\
\hline
\end{tabular}

$* \mathrm{p}<0.05$.

Among the group of patients with pulmonary tuberculosis and concurrent insulin resistance on admission to the hospital, the indices of TC were generally higher than those obtained in the group of patients without insulin resistance. The minimum level of TC in group 1 (TB / IR) was $3.3 \mathrm{mmol} / \mathrm{L}$, and the maximum was $7.95 \mathrm{mmol} / \mathrm{L}$. For group 2 (TB), these values were $2.94 \mathrm{mmol} / \mathrm{L}$ and $6.08 \mathrm{mmol} / \mathrm{L}$, respectively. Medial values of TC indices differed at a statistically significant level between groups $(p=0.012)$ : group $1(\mathrm{~TB} /$ IR) $-4.82 \mathrm{mmol} / \mathrm{L}$, group 2 (TB) $-4.25 \mathrm{mmol} / \mathrm{L}$.

Plasma TG level was also higher in group 1 (TB / IR) patients $-1.32 \mathrm{mmol} / \mathrm{L}$ than in group 2 (TB) patients $-1.28 \mathrm{mmol} / \mathrm{L}$ (medial values are given). However, no statistical significance was obtained in this difference.

As well as when comparing the Medial values of HDL cholesterol were lower in patients with TB and insulin resistance than in those who didn 't have insulin resistance $(0.98 \mathrm{mmol} / \mathrm{L}$ and $1.09 \mathrm{mmol} /$ L). The median VLDL cholesterol values were almost indistinguishable between group 1 (TB / IR) and group 2 (TB) $(0.6 \mathrm{mmol} / \mathrm{L}$ and $0.58 \mathrm{mmol} / \mathrm{L}$, respectively).

LDL cholesterol values were higher in patients of group 1 (TB / IR) and ranged from $1.6 \mathrm{mmol} / \mathrm{L}$ to $6.5 \mathrm{mmol} / \mathrm{L}$ with a median value of $3.2 \mathrm{mmol} / \mathrm{L}$, compared with patients in group 2 (TB): the minimum level is $1.0 \mathrm{mmol} / \mathrm{L}$, the maximum is $4.3 \mathrm{mmol} / \mathrm{L}$, the medial value is $2.5 \mathrm{mmol} / \mathrm{L}$. The obtained difference was statistically significant $(\mathrm{p}=0.004)$.

The atherogenic index was higher in the group of patients with tuberculosis who had insulin resistance $(\mathrm{p}=0.005)$. Its medial value was 3.9 units against 2.8 units in patients with tuberculosis without insulin resistance.

Our study revealed that those pulmonary tuberculosis patients, who was diagnosed with concurrent insulin resistance had severe course of tuberculosis. The majority of these patients complained of fever, severe fatigue and weakness, profuse sweating, weight loss, cough and shortness of breath. Decreased insulin sensitivity may occur due to disruption of various molecular 
pathways. The exact underlying cause of insulin resistance remains unclear, with a number of key mechanisms proposed, including oxidative stress, inflammation, insulin receptor mutations, endoplasmic reticulum stress, and mitochondrial dysfunction $[8,9]$. Therefore, we make the assumption that the development of insulin resistance in patients with tuberculosis was associated with the severe course of the disease.

Our study also revealed significant disorders of lipid metabolism (increase in the levels of total cholesterol, low-density lipoprotein cholesterol and atherogenic index) in pulmonary tuberculosis patients with concurrent insulin resistance. The same changes were found by other scientists $[10$, 11] and can be explained as the systemic alteration of lipid metabolism by insulin resistance, which then leads to the development of dyslipidemia and the well-known lipid triad: high levels of plasma triglycerides, low levels of highdensity lipoprotein, and the appearance of small dense low-density lipoproteins

\section{Conclusions}

Insulin resistance in pulmonary tuberculosis patients was associated with severe course of the disease, severe clinical manifestations and impaired external respiration.

Pro-atherogenic disorders of lipid metabolism in pulmonary tuberculosis patients with concurrent insulin resistance can be considered as the degree of endogenous intoxication.

\section{Declarations:}

\section{Statement of Ethics}

The authors have no ethical conflicts to disclosure.

\section{Consent for publication}

All authors give their consent to publication. Disclosure Statement

The authors have no potential conflicts of interest to disclosure.

\section{Funding Sources}

This study was not supported by any grants from public, commercial or other sectors

\section{Data Transparency}

The data can be requested from the authors.

\section{References}

1. Dean, J.M., Lodhi, I.J. (2018). Structural and functional roles of ether lipids. Protein Cell., 9(2), 196-206. doi: 10.1007/s13238-017-0423-5.

2. de Carvalho, C.R., Caramujo, M.J.(2018). The Various Roles of Fatty Acids. Molecules., 23(10), 258-264. doi: 10.3390/molecules23102583.

3. Bernardi, S., Marcuzzi, A., Piscianz, E., Tommasini, A., Fabris, B. (2018). The Complex Interplay between Lipids, Immune System and Interleukins in Cardio-Metabolic Diseases., 19(12). doi: 10.3390/ ijms19124058.

4. Traini, M., Kritharides, L. (2017). Lipids grease the wheels of the immune system. Curr Opin Lipidol., 28(6), 516-517. doi: 10.1097/MOL.0000000000000464.

5. Gebremicael, G., Amare, Y., Challa, F., et al. (2017). Lipid Profile in Tuberculosis Patients with and without Human Immunodeficiency Virus Infection. Int J Chronic Dis. doi:10.1155/2017/3843291

6. Gago, G., Diacovich, L., Gramajo, H. (2018). Lipid metabolism and its implication in mycobacteriahost interaction. Curr Opin Microbiol. 36-42. doi: 10.1016/j.mib.2017.11.020.

7. Vrieling, F., Ronacher, K., Kleynhans, L., van den Akker, E., Walzl, G., Ottenhoff, T., \& Joosten, S. A. (2018). Patients with Concurrent Tuberculosis and Diabetes Have a Pro-Atherogenic Plasma Lipid Profile. EBioMedicine, 32, 192-200. https://doi.org/10.1016/j.ebiom.2018.05.011

8. Yaribeygi, H., Farrokhi, F.R., Butler, A.E., Sahebkar, A. (2019). Insulin resistance: Review of the underlying molecular mechanisms. J Cell Physiol., 234(6), 8152-8161. doi: 10.1002/jcp.27603.

9. Rivas, A.M., Nugent, K. (2021). Hyperglycemia, Insulin, and Insulin Resistance in Sepsis. Am J Med Sci., 361(3), 297-302. doi: 10.1016/j.amjms.2020.11.007.

10. Ormazabal, V., Nair, S., Elfeky, O. et al. (2018). Association between insulin resistance and the development of cardiovascular disease. Cardiovasc Diabetol. 17, 122-130. https://doi.org/10.1186/s12933018-0762-4

11. Shvets O.M. (2018) Study of lipid profile in patients with pulmonary tuberculosis on the background of insulin resistance [Shvec', O.M. (2018) Vyvchennja lipidnogo profilju u hvoryh na tuberkul'oz legeniv na tli insulinorezystentnosti. Ukrai'ns'kyj zhurnal ekstremal'noi' medycyny im. G.O. Mozhajeva. 3, 74-80.] 